\title{
Compensation Payments and Animal Disease: Incentivising Farmers Both to Undertake Costly On-farm Biosecurity and to Comply with Disease Reporting Requirements
}

\author{
$\operatorname{Rob}_{\text {Fraser }^{1}}$
}

Accepted: 20 November 2016 / Published online: 2 December 2016

(C) The Author(s) 2016. This article is published with open access at Springerlink.com

\begin{abstract}
This paper examines the issue of compensation payments for farmers affected by an animal disease outbreak. Recent literature has questioned the scope for the widely used "single mechanism" of compensation payments to incentivise farmers both to undertake costly on-farm biosecurity and to comply with disease reporting requirements. This paper develops a simple theoretical model of the farmer's decision environment in this situation and uses a numerical analysis to illustrate both the potential for a range of levels of compensation payments to achieve this dual incentivising, and how this range is affected by changes in the parameter values of the farmer's decision environment. The findings of the paper are used to suggest a range of policy implications in relation to compensation payments in the UK.
\end{abstract}

Keywords Compensation payments · Animal disease · Incentivising farmers · On-farm biosecurity $\cdot$ Disease reporting requirements

\section{Introduction}

According to the National Audit Office (NAO) report on the outbreak of Foot-and-Mouth Disease in the UK in 2001 "Farmers received over $£ 1.1 \mathrm{~b}$ in compensation for animals that were slaughtered for disease control purposes" (NAO 2002), within a total public sector cost of over $£ 3$ b. In addition, Olmstead and Rhode (2015) in their historical evaluation of animal disease policy in the United States point out the large share of compensation (indemnity) payments in the total cost of a range of disease eradication attempts.

Nevertheless, as argued by Olmstead and Rhode "eradication... would demand devising incentive-compatible compensation schemes" (p. 279) which would "create incentives for farmers to participate" (p. 283) in reporting disease outbreaks on their farms. However, such

Rob Fraser

r.w.fraser@kent.ac.uk

1 School of Economics, University of Kent, Canterbury, UK 
compensation payments to farmers have often been criticised, ${ }^{1}$ and government agencies under pressure to reduce them. In this context Bicknell et al. (1999) report that the New Zealand Animal Health Board's "latest national Tb strategy" stipulates that "compensation payments will be reduced" (p. 514) and on this basis they proceed to evaluate the impact of eliminating compensation payments on farmer behaviour. Using "a dynamic bioeconomic model of livestock disease control" (p. 501) they find that although "producers take a more active role in controlling the spread of disease within their herds", in the presence of voluntary testing for disease "the elimination of compensation leads to a decrease in testing activity" (p. 514). As a consequence, where disease notification is mandatory Bicknell et al. (1999) point out that "the elimination of compensation payments may prompt non-compliant behaviour" (p. 514).

Moreover, this problem of clashing incentives for on-farm biosecurity versus reporting disease outbreaks in the context of compensation payments has been highlighted again recently by Hennessy and Wolf (2015) who suggest that "compensation must be sufficient to ensure early reporting but not so large as to discourage appropriate levels of biosecurity effort" (p. 1). But in developing this argument Hennessy and Wolf (2015) then go on to cite the analysis of Gramig et al. (2009) and on this basis reach the conclusion that "a simple onesize-fits-all indemnity payment could not deal with both problems" (p. 9) - which is at odds with actual disease control policy where "Animal health authorities have relied on a single mechanism - indemnities - to facilitate both ex ante biosecurity effort and ex post reporting" (p. 9).

However, although Hennessy and Wolf (2015) "explore the incentives that indemnities offer", they do so using "a direct, discursive and non-mathematical approach" (p. 2). Therefore, this conflict between the widespread and on-going animal disease policy of using a single incentive mechanism, compensation payments, to deliver both "appropriate levels of biosecurity" and "ensure disease reporting" and Hennessy and Wolf's conclusion that such an approach "could not deal with both problems", suggests it might be worthwhile undertaking a more mathematical approach to analysing this situation, with a view to throwing more light on the trade-off of farmer incentives associated with varying levels of compensation payments.

Such an analysis is reported in what follows. Section 2 develops a simple model of farmer decision-making in the presence of the threat of animal disease-and where the farmer must make sequential decisions regarding: (i) whether to choose to undertake voluntary onfarm biosecurity measures which are costly, but which would reduce the risk of a disease outbreak; and (ii) whether to comply or not with the mandatory requirement to report (notify) an outbreak of disease should it subsequently take place on the farm. It should be noted at this point that although the choice of whether or not to report a disease outbreak fits readily into such a binary choice format, framing the decision about investing in on-farm biosecurity measures as a binary choice is less realistic. More specifically, farmers are likely to have a range of biosecurity measures to choose from, with associated implications both for the cost of implementation and for the impact on the risk of an outbreak. In addition, this specification in effect excludes consideration of both spatial and temporal externalities in relation to disease outbreaks. Therefore, while this simplified approach is maintained for the analysis to follow, its implications for policy are considered in the Conclusion. ${ }^{2}$

${ }^{1}$ For example: "Foot and mouth payments are too high" www.theguardian.com/uk/2001/aug/07/politics. footandmouth.

${ }^{2}$ I am grateful to an anonymous reviewer for drawing my attention to these limitations in the analysis to follow, and for suggesting their inclusion in the discussion of the paper's policy implications. 
This model is then subjected to a numerical analysis in Sect. 2, which evaluates the role of a range of policy and other parameters of the farmer's decision environment in determining the scope for animal health agencies to use compensation payments to provide appropriate incentives both for the implementation of on-farm biosecurity and for compliance behaviour in relation to disease reporting. Note in this context that the parameter values used in the numerical analysis are largely chosen for illustrative purposes. In particular, the NAO report cited above points out that the UK's Animal Health Act 1981 "requires compensation to be based on the value of the animal immediately before it became infected"-where the government's interpretation of "value" "is that compensation will be based on "market value", (NAO 2002, p. 82). Therefore, the exploration in what follows of the scope for such payments to be varied is in effect a hypothetical consideration of cost-effectiveness options within the context of the legal requirement for compensation to be paid as provided by the UK's Animal Health Act 1981.

Finally, the Conclusion provides both a brief summary and a discussion of policy implications, with particular reference to the issues of spatial heterogeneity in disease prevalence, flexibility in the implementation of on-farm biosecurity and the contribution of the paper to the debate over the size of compensation payments as required by UK law.

\section{The Model}

The incentive effects of compensation payments in the context of animal disease have previously been analysed by Gramig et al. (2009) using a dynamic, stochastic capital valuation model of on-farm decision-making while, as stated previously, Hennessy and Wolf (2015) used a discursive, non-mathematical approach. Yet both reach the same conclusion that "By using a single mechanism to induce biosecurity and reporting simultaneously, the incentives for each individual private action are not clear" (Gramig et al. 2009, p. 639; see also Hennessy and Wolf 2015, p. 10).

As a consequence, this paper takes a "middle-ground" approach in terms of analytical complexity, with the aim of balancing the need for enough model structure to be able to characterise the farmer's disease management decision problems with the desire to provide clarity both in relation to the incentive effects of compensation payments, and (therefore) in relation to the scope for animal health agencies to use compensation payments to best effect. It should be emphasised at this point that although the objective of the government in this context can reasonably be thought of as one of maximising social welfare, the analysis in this paper forms only a component of a full policy evaluation exercise. In particular, as indicated in the Introduction, the focus of the analysis in this paper is limited to a consideration of the cost-effectiveness of alternative policy options in relation to the level of compensation payments. As such, it does not enable consideration of the social desirability (or not) of the payment of such compensation-a consideration which, since these payments are required by law, is outside the scope of this paper. ${ }^{3}$

In what follows the farmer is assumed to be an expected utility maximiser within a decision environment characterised by uncertainty about a disease outbreak. Given this uncertainty, the farmer must make two decisions: (i) whether to incur the cost of on-farm biosecurity measures which will reduce the likelihood of a disease outbreak; and (ii) whether to report a disease outbreak should one take place. Note that, reflecting the actual legal position of

3 I am grateful to an anonymous reviewer for pointing out this limitation in the scope of the paper's analysis. See also NAO (2002) for a consideration of the cost-effectiveness issue. 
livestock farmers in the UK, the first decision is voluntary for farmers, while the second decision relates to a legal requirement (see NAO 2002). In addition, this decision-making environment has a temporal feature in that information about a disease outbreak is only revealed after the on-farm biosecurity costs are incurred (or not), and after which event the farmer must decide whether or not to report a disease outbreak (should one have taken place). Nevertheless, in what follows the analysis of these decisions is framed in an ex ante context so that the farmer is evaluating four options: ${ }^{4}$

(i) Incur biosecurity costs and report any disease outbreak (BR).

(ii) Incur biosecurity costs but don't report any disease outbreak (BNR).

(iii) Don't incur biosecurity costs, but report any disease outbreak (NBR).

(iv) Don't incur biosecurity costs and don't report any disease outbreak (NBNR).

In addition, the (risk averse) farmer faces uncertainty not just in relation to the likelihood of a disease outbreak, but also in relation to the likelihood of non-compliance with the requirement to report a disease outbreak being detected. ${ }^{5}$ Finally, as stated in the Introduction, the farmer's decision environment is closed in that that are no spillovers to future decision contexts on the farm or to the decision contexts of other farmers. The removal of such spillovers is a major analytical simplification, the implications of which are considered, particularly in a spatial context, in the Conclusion to this paper.

More specifically:

(i) If the farmer's livestock remain disease free they are assumed to have a "value" M.

(ii) If the farmer chooses to incur the cost of on-farm biosecurity measures (B) then the likelihood of no disease outbreak is increased from q to $p$ (i.e. $p>q$ ).

(iii) If the farmer experiences a disease outbreak and chooses to report it, then the farmer is paid compensation of $\mathrm{D}$, where $0<\mathrm{D}<\mathrm{M}$, and is the government agency's "single mechanism" for providing incentives both to undertake on-farm biosecurity measures and to report a disease outbreak. ${ }^{6}$

(iv) If the farmer experiences a disease outbreak and chooses not to report it, then the livestock can be disposed of for a "quick sale" value of $\mathrm{S}$ (where $\mathrm{S}<\mathrm{M}$ ). In addition, the likelihood of not being caught so doing is $r$, but if caught then the government agency imposes a penalty of $\mathrm{tD}$ (where $\mathrm{t}>0$ ). Note that if $\mathrm{t}=1$, then this is equivalent to the government agency imposing a fine equal to the full amount of the compensation which

\footnotetext{
4 Note that although the farmer would in practice have the option of reviewing the ex ante decision to report or not report once the disease outbreak information was revealed, it is shown in the numerical analysis in the next section that whichever of these decisions is preferred ex ante remains the preferred decision after the disease outbreak information is revealed.

5 For example, bovine tuberculosis is a notifiable disease and therefore farmers have a legal requirement to report an outbreak on their farm. Note also that Hennessy and Wolf (2015) and Gramig et al. (2009) frame the reporting decision as "hidden in formation" and characterise this as an adverse selection problem, while the on-farm biosecurity decision is framed as "hidden action" and characterised as a moral hazard problem. But in my view "hidden information" can be either adverse selection (if it is legal to hide the information) or moral hazard (if it is illegal to hide the information). Similarly, "hidden action" can be either adverse selection (again if it is legal to hide the action) or moral hazard (again if it is illegal to hide the action). See Fraser (2015) for a detailed discussion of these distinctions, but in what follows, because on-farm biosecurity in the context of animal disease is not mandatory, I see this as an adverse selection problem, and because reporting a disease outbreak is mandatory, I see this as a moral hazard problem. Finally, note the same distinction applies in relation to tax avoidance (i.e. adverse selection) and tax evasion (i.e. moral hazard).

6 As stated in the Introduction, it should be recalled at this point that the current legal requirement in the UK is effectively for $\mathrm{D}=\mathrm{M}$. Therefore, an analysis which considers the cost-effectiveness of $\mathrm{D}<\mathrm{M}$ is hypothetical within the context of the law.
} 
would have been paid if the farmer had reported the disease outbreak. ${ }^{7}$ Note also that Hennessy and Wolf (2015) suggest "the indemnity must at least equal the amount the farmer would receive" "to quietly market the (diseased) animals" (p. 7). This suggestion creates the hypothesis that to achieve compliance $\mathrm{D}>\mathrm{S}$, an hypothesis which will be evaluated in the numerical analysis of the next section.

On this basis the expected utility of net income $(E(U(I)))$ for each of the farmer's four options is given by:

(i) BR:

$$
\mathrm{E}(\mathrm{U}(\mathrm{I}))=\mathrm{E}(\mathrm{U}(\mathrm{pM}+(1-\mathrm{p}) \mathrm{D}-\mathrm{B}))
$$

(ii) BNR:

$$
\mathrm{E}(\mathrm{U}(\mathrm{I}))=\mathrm{E}(\mathrm{U}(\mathrm{pM}+(1-\mathrm{p})(\mathrm{rS}+(1-\mathrm{r})(\mathrm{S}-\mathrm{tD}))-\mathrm{B}))
$$

(iii) NBR:

$$
\mathrm{E}(\mathrm{U}(\mathrm{I}))=\mathrm{E}(\mathrm{U}(\mathrm{qM}+(1-\mathrm{q}) \mathrm{D}))
$$

(iv) NBNR:

$$
\mathrm{E}(\mathrm{U}(\mathrm{I}))=\mathrm{E}(\mathrm{U}(\mathrm{qM}+(1-\mathrm{q})(\mathrm{rS}+(1-\mathrm{r})(\mathrm{S}-\mathrm{tD})))
$$

The next section reports on a numerical analysis of the farmer's choice between these four options, with a particular focus on the potential for the value of $\mathrm{D}$ to be chosen by the government agency such that option (i) (i.e. undertaking on-farm biosecurity measures and reporting a disease outbreak) is preferred by the farmer. In addition, the numerical analysis evaluates the role of various parameters of the farmer's decision environment in influencing this potential (specifically: the farmer's attitude to risk; the (base level) likelihood of no disease outbreak (q); the cost of on-farm biosecurity measures (B); the value of "quietly marketed" diseased animals $(\mathrm{S})$; and the likelihood of not being caught not reporting a disease outbreak (r)).

However, before proceeding it should be noted that there is a particular complexity to the farmer's decision of whether to incur the cost of on-farm biosecurity measures which relates to the base level of the likelihood of no disease outbreak for the farmer. More specifically, incurring this cost (B) increases the likelihood of no disease outbreak (i.e. $p>q$ ). Given this: ${ }^{8}$

$$
\mathrm{dE}(\mathrm{I}) / \mathrm{dq}=(\mathrm{M}-\mathrm{D})>0
$$

Therefore, for a risk neutral farmer, the decision to incur the cost of on-farm biosecurity measures will depend on the balance between the positive impact of this action on expected income (i.e. see Eq. 5) and the negative impact of the cost itself.

But for a risk averse farmer, this action also has an effect of the variance of income (Var(I)) where: ${ }^{9}$

$$
\operatorname{Var}(\mathrm{I})=\mathrm{q}(\mathrm{M}-\mathrm{E}(\mathrm{I}))^{2}+(1-\mathrm{q})(\mathrm{D}-\mathrm{E}(\mathrm{I}))^{2}
$$

\footnotetext{
${ }^{7}$ Note that in the Gramig et al. (2009) analysis (the equivalent of) $t$ is used as an additional policy mechanism, so that the government agency uses "(a) indemnities to achieve desired levels of biosecurity and (b) fines that induce disclosure of disease status" (p. 639). In what follows, only D is used to deliver these incentives, as is consistent with current disease control policy. However, the role of varying t is considered within the context of the sensitivity analysis in the next section.

8 From Eq. (3).

${ }^{9}$ Recall that $\operatorname{Var}(\mathrm{I})=\mathrm{E}(\mathrm{I}-\mathrm{E}(\mathrm{I}))^{2}$.
} 
More specifically, differentiating Eq. (6) with respect to q and rearranging gives:

$$
\mathrm{d} \operatorname{Var}(\mathrm{I}) / \mathrm{dq}=(\mathrm{M}-\mathrm{D})^{2}(1-2 q)
$$

which implies:

$$
\mathrm{d} \operatorname{Var}(\mathrm{I}) / \mathrm{dq}>\text { or }<0 \text { as } \mathrm{q}<\text { or }>1 / 2
$$

In words, Eq. (8) implies that if the farmer is facing a relatively high base level likelihood of a disease outbreak (i.e. $\mathrm{q}<1 / 2$ ), then although incurring the cost of on-farm biosecurity measures increases expected income by reducing this likelihood, it also increases the variance of income in this situation. Only if the base level likelihood of a disease outbreak is relatively low (i.e. $\mathrm{q}>1 / 2$ ) does incurring the cost of on-farm biosecurity measures have an overall risk-reducing impact. It follows that for endemic animal diseases such as bovine tuberculosis (in the UK) which have a strong spatial variation in terms of disease prevalence, the incentive for a farmer to undertake on-farm biosecurity measures will also have a spatial variation. This policy issue is explored further in the numerical analysis of the next section.

\section{Numerical Analysis}

In order to undertake a numerical analysis of the model developed in Sect. 2 it is further assumed that the attitude to risk of the farmer can be represented by the mean-variance framework and the constant relative risk aversion functional form: ${ }^{10}$

$$
E(U(I))=U(E(I))=1 / 2 . U^{\prime \prime}(E(I)) \cdot \operatorname{Var}(I)
$$

where

$$
U(I)=I^{(1-R)} /(1-R)
$$

and $\mathrm{R}=$ constant coefficient of relative risk aversion $=-\mathrm{U}^{\prime \prime}(\mathrm{I}) \cdot \mathrm{I} / \mathrm{U}^{\prime}(\mathrm{I})$

with $U^{\prime}(\mathrm{I})$ and $\mathrm{U}^{\prime \prime}(\mathrm{I})$ denoting the first and second derivatives respectively of the utility function $\left(\mathrm{U}^{\prime}(\mathrm{I})>0 ; \mathrm{U}^{\prime \prime}(\mathrm{I})<0\right)$.

Note than an advantage of using this framework is that it clearly distinguishes the expected income and variance of income components of the incentive effects of compensation payments in determining the farmer's decisions regarding on-farm biosecurity and disease reporting. And as will be shown below, this simple framework also helps to clarify the impact of changes in the parameter values of the farmer's decision environment on the preferred choice of actions. Given this framework, the assumed model parameter values for the Base Case are given in Table 1.

In relation to these assumed parameter values, the following points should be noted;

(a) Given the current legal requirement in the $\mathrm{UK}$ for $\mathrm{D}=\mathrm{M}$, in what follows the ratio $\mathrm{D} / \mathrm{M}$ will be central to the consideration of the cost-effectiveness of alternative levels of compensation payments.

(b) The fixing of $\mathrm{r}$ and $\mathrm{t}$, while also consistent with the current application of the compensation policy in the UK, nevertheless removes further scope for, potentially socially desirable, policy alternatives. In this context, Fraser (2002) analyses the potential for adjusting both $\mathrm{r}$ and $\mathrm{t}$ to encourage compliance behaviour among farmers, while also

10 See Hanson and Ladd (1991) and Pope and Just (1991) for arguments supporting these assumptions. 
Table 1 Specification of the Base Case

\begin{tabular}{lll}
\hline Model parameter & Description of model parameter & Base Case value \\
\hline M & Disease free value of farmer's livestock & 100 \\
$\mathrm{~S}$ & Disposal value of livestock from a "quick sale" & 50 \\
$\mathrm{~B}$ & Cost of on-farm biosecurity & 10 \\
$\mathrm{q}$ & Probability of no disease outbreak without biosecurity & 0.55 \\
$\mathrm{p}$ & Probability of no disease outbreak with biosecurity & 0.75 \\
$\mathrm{r}$ & Probability of not being caught for non-compliance & 0.9 \\
$\mathrm{t}$ & Non-compliance penalty rate & 1 \\
$\mathrm{R}$ & Farmer's attitude to risk & 0.5 \\
$\mathrm{D}$ & Compensation paid for reporting a disease outbreak & 46 \\
\hline
\end{tabular}

Table 2 Results for the Base Case

\begin{tabular}{lrrrr}
\hline & (i) $\mathrm{BR}$ & (ii) $\mathrm{BNR}$ & (iii) $\mathrm{NBR}$ & (iv) $\mathrm{NBNR}$ \\
\hline $\mathrm{E}(\mathrm{I})$ & 76.50 & 76.35 & 75.70 & 75.43 \\
$\operatorname{Var}(\mathrm{I})$ & 646.75 & 706.58 & 721.71 & 823.54 \\
$\mathrm{E}(\mathrm{U}(\mathrm{I}))$ & 17.25 & 17.21 & 17.13 & 17.06 \\
\hline
\end{tabular}

reducing monitoring costs. ${ }^{11}$ This issue will also be considered in the sensitivity analysis to follow.

(c) The setting of $\mathrm{R}=0.5$ is consistent with existing empirical evidence (see Newbery and Stiglitz 1981, and Bardsley and Harris 1987).

Note also that for the Base Case the farmer's baseline situation is "favourable" in that a disease outbreak is relatively unlikely (i.e. $q>0.5$ ). As a consequence, and recalling the analysis in Sect. 2, incurring the cost of on-farm biosecurity measures will deliver both an increase in expected income (before the cost of these measures) and a decrease in the variance of income for the farmer. Finally, note that the "fine" for non-compliance has been set equal to the full amount of the compensation payment (i.e. $\mathrm{t}=1$ ). This is consistent with practice in the UK (NAO 2002).

Table 2 provides details of the results of the numerical analysis using these Base Case parameter values. $^{12}$

These results show that, given the other parameter values in the farmer's decision environment, by choosing a level of compensation payment of 46 the government agency creates a situation where the farmer's expected income is maximised, and variance of income is minimised, for the option where the farmer chooses both to undertake costly on-farm biosecurity measures and to report a disease outbreak in the event that one takes place (i.e. BR). It follows that this Base Case represents a situation where the government agency is able to

\footnotetext{
11 I am again grateful to an anonymous reviewer for pointing out the policy relevance of varying both $r$ and $t$ in this context.

12 Note that while the Base Case parameter values have been chosen to deliver BR as the optimal decision, as will be clear in the sensitivity analysis which follows, the scope for setting D to deliver this set of choices is extremely limited. Hence, the extent to which the $\mathrm{E}(\mathrm{U}(\mathrm{I}))$ for BR exceeds the alternatives is relatively small. I am again grateful to an anonymous reviewer for making this point as this feature of the numerical analysis has important policy implications.
} 
Table 3 Sensitivity with respect to D

\begin{tabular}{llllll}
\hline & $\mathrm{D}(\% \mathrm{D} / \mathrm{M})$ & & & & \\
\cline { 2 - 6 } & $43(43 \%)$ & 45.2 & 46 & 50.5 & $52(52 \%)$ \\
\hline $\mathrm{R}=0.2$ & $\mathrm{BNR}$ & $\mathrm{BNR}$ & $\mathrm{BR}$ & $\mathrm{NBR}$ & $\mathrm{NBR}$ \\
$\mathrm{R}=0.5$ & $\mathrm{BNR}$ & $\mathrm{BR}$ & $\mathrm{BR}$ & $\mathrm{BR}$ & $\mathrm{NBR}$ \\
\hline
\end{tabular}

use the single mechanism of compensation payments to incentivise the farmer not only to incur the private cost of reducing their likelihood of a disease outbreak, but also to choose to comply with their disease reporting requirement. Note also that this Base Case result features $\mathrm{D}<\mathrm{S}$, which implies the compensation payment is less than the amount the farmer would receive from "quietly marketing" their diseased animals. This contradiction of the hypothesis suggested by Hennessy and Wolf (2015) can be explained by comparing the results in columns (i) and (ii) which show that, given the farmer has chosen to incur the cost of on-farm biosecurity measures, not only does the expected income from complying exceed that from not complying, but also the variance of income is lower. Moreover, these differences can be attributed to a combination of the likelihood of being caught, and the associated fine, in modifying the farmer's expected income and variance of income. ${ }^{13}$

Now that it has been established that the potential exists for a government agency to be able to set the level of compensation payments to incentivise both the undertaking of on-farm biosecurity measures and disease reporting compliance, consider next the range of values over which this level can be successfully varied. Table 3 contains results from varying the value of $\mathrm{D}$ between 43 and 52, and shows the preferred choice of actions by a farmer with two different levels of risk aversion (i.e. $\mathrm{R}=0.2$ and 0.5 ).$^{14}$

The results in Table 3 show that if the government agency was to reduce the level of compensation payments to 43 , then both types of farmers would choose to incur the cost of on-farm biosecurity measures, but not to report a disease outbreak (i.e. BNR). In this case, although the next best option is BR, given the level of $\mathrm{D}$, the risk of being caught not complying and the associated fine, expected income is higher and the variance of income is lower for BNR. ${ }^{15}$ Whereas if the government agency was to reduce the level of compensation payment only to 45.2 , then this level represents a borderline where for the less risk averse farmer (i.e. $\mathrm{R}=0.2$ ) the expected income advantage of on-farm biosecurity measures and not complying (i.e. BNR) is sufficient to dominate the variance of income advantage of on-farm biosecurity measures and complying (i.e. BR), but this is not the case for the more risk averse farmer (i.e. $\mathrm{R}=0.5$ ).

Similarly, if the government was to increase the level of compensation payment to 52 , then the expected income advantage of not incurring the cost of on-farm biosecurity measures, but reporting a disease outbreak (i.e. NBR) dominates the farmer's decision regardless of

\footnotetext{
${ }^{13}$ Following on from the discussion in Sect. 2, in the event of a disease outbreak E(I) from complying is 46 (i.e. =D), compared with 45.2 by not complying (see Eq. 2 ). In addition, complying is a riskless choice for a risk averse farmer.

14 Note that the values of $\mathrm{D}$ in this table, and in the subsequent tables, are chosen to illustrate the set of values of $\mathrm{D}$ which capture changes in the optimal decision choices for the farmer. For lower and higher values of $\mathrm{D}$ than contained in the tables there are no further changes in decision choices.

15 In this case also note that in the event of a disease outbreak, E(I) from complying is 43 compared with 45.7 for not complying. Moreover, not complying remains the preferred choice of action for a risk averse farmer even after a disease outbreak is revealed because this expected income difference dominates the higher risk associated with this choice.
} 
Table 4 Sensitivity with respect to $\mathrm{B}$

\begin{tabular}{llllll}
\hline & $\mathrm{D}(\% \mathrm{D} / \mathrm{M})$ & & & & \\
\cline { 2 - 5 } & $43(43 \%)$ & 45.2 & 46 & 60.3 & $61(61 \%)$ \\
$\mathrm{B}=8$ & & & & \\
$\mathrm{R}=0.5$ & $\mathrm{BNR}$ & $\mathrm{BR}$ & $\mathrm{BR}$ & $\mathrm{BR}$ & $\mathrm{NBR}$ \\
$\mathrm{B}=12$ & & & & & \\
$\mathrm{R}=0.5$ & $\mathrm{NBNR}$ & $\mathrm{NBR}$ & $\mathrm{NBR}$ & $\mathrm{NBR}$ & $\mathrm{NBR}$ \\
\hline
\end{tabular}

the level of risk aversion. However, if this increase was only to the level of 50.5, then while the expected income advantage of NBR dominates for the less risk averse farmer, for the more risk averse farmer the variance of income advantage of on-farm biosecurity measures dominates overall and BR is preferred.

It follows from the results in Table 3 that for the Base Case parameter values the "window" open to the government agency for setting a level of compensation payments which incentivises both on-farm biosecurity and disease reporting compliance ranges between 45.2 and 50.5 (i.e. between 45.2 and $50.5 \%$ of the "market value" M) — and where this "window" is smaller for less risk averse farmers, and larger for more risk averse farmers. Moreover, for levels of compensation payments above this range the farmer is not incentivised to incur the cost of on-farm biosecurity measures, while for levels of compensation payments below this range the farmer is not incentivised to comply with their disease reporting requirements. Given that the legal requirement in the UK is effectively for $\mathrm{D}=\mathrm{M}$, it is clear from Table 3 both that this level of compensation payment means that farmers have no incentive to voluntarily implement (costly) on-farm biosecurity, and that (hypothetically) substantial increases in cost-effectiveness could therefore be achieved by reducing the level of compensation paid below "market value".

Next, consider the impact of variations in the Base Case parameter values on the size of this "window" of levels of compensation payments which incentivise both on-farm biosecurity and disease reporting compliance. First Table 4 contains details of the results for a decrease and an increase in the Base Case cost of on-farm biosecurity measures (i.e. $B=8$ and 12). ${ }^{16}$

The results in Table 4 show that if the cost of on-farm biosecurity measures is reduced from the Base Case level (i.e. to $\mathrm{B}=8$ ), then the "window" of levels of compensation payments available to the government agency increases considerably from between 45.2 and 50.5 to between 45.2 and 60.3, at which point the farmer prefers not to incur the cost of on-farm biosecurity measures. Whereas if the cost of on-farm biosecurity measures is increased from its Base Case value (i.e. to $\mathrm{B}=12$ ) then this "window" disappears completely in that at no level of compensation payments is incurring the cost of on-farm biosecurity measures worthwhile. In this case, as the results in Table 4 show, the only changes in farmer choice as $\mathrm{D}$ is varied relate to whether or not to comply with the disease reporting requirement.

Second, Table 5 contains details of the results for a decrease and an increase in the Base Case value from a "quick sale" of diseased animals (i.e. the value of $S$ ), rather than reporting a disease outbreak.

The results in Table 5 show that if the value of "quietly marketing" diseased animals is decreased (i.e. to $\mathrm{S}=45$ ) then the "window" of levels of compensation payments available to the government agency increases from between 45.2 and 50.5 to between 40.7 and 50.5 ,

16 Note that increasing and decreasing the gap between $\mathrm{p}$ and $\mathrm{q}$ delivered by on-farm biosecurity measures has similar effects on the "window" to those of decreasing and increasing B, so these results are not provided here. 
Table 5 Sensitivity with respect to $\mathrm{S}$

\begin{tabular}{lllllll}
\hline & $\mathrm{D}(\% \mathrm{D} / \mathrm{M})$ & & & & & \\
\cline { 2 - 6 } & $40(40 \%)$ & 40.7 & 46 & 49.6 & 50.5 & $52(52 \%)$ \\
\hline $\mathrm{S}=45$ & & & & & & \\
$\mathrm{R}=0.5$ & $\mathrm{BNR}$ & $\mathrm{BR}$ & $\mathrm{BR}$ & $\mathrm{BR}$ & $\mathrm{BR}$ & $\mathrm{NBR}$ \\
$\mathrm{S}=55$ & & & & & & \\
$\mathrm{R}=0.5$ & $\mathrm{BNR}$ & $\mathrm{BNR}$ & $\mathrm{BNR}$ & $\mathrm{BR}$ & $\mathrm{BR}$ & $\mathrm{NBR}$ \\
\hline
\end{tabular}

\begin{tabular}{cllllll}
\hline & $\mathrm{D}(\% \mathrm{D} / \mathrm{M})$ & & & & & \\
\cline { 2 - 7 } & $40(40 \%)$ & 43.1 & 44 & 47.4 & 50.5 & $52(52 \%)$ \\
\hline $\mathrm{r}=0.85$ & & & & & & \\
$\mathrm{R}=0.5$ & $\mathrm{BNR}$ & $\mathrm{BR}$ & $\mathrm{BR}$ & $\mathrm{BR}$ & $\mathrm{BR}$ & $\mathrm{NBR}$ \\
$\mathrm{r}=0.95$ \\
$\mathrm{R}=0.5$ & $\mathrm{BNR}$ & $\mathrm{BNR}$ & $\mathrm{BNR}$ & $\mathrm{BR}$ & $\mathrm{BR}$ & $\mathrm{NBR}$ \\
\hline
\end{tabular}

Table 6 Sensitivity with respect to $\mathrm{r}$

reflecting the associated decreased attraction of not complying with the disease reporting requirement. However, if the value of "quietly marketing" diseased animals is increased (i.e. to $S=55$ ) then the associated increased attraction of not complying results in a decrease in the "window" to between 49.6 and 50.5 (Hennessy and Wolf 2015).

It follows that, while a lower cost of on-farm biosecurity measures and a lower value for "quietly marketed" diseased animals enhances the scope for a government agency to set the level of compensation payments to incentivise both on-farm biosecurity and disease reporting compliance, increases in these values can reduce or even eliminate this scope.

A similar finding applies in the case of variations in the likelihood of being caught not complying (i.e. r), as reported in Table $6 .^{17}$

In this case, decreasing the likelihood of not being caught (to $r=0.85)$ increases the attraction of complying and so the "window" is increased from between 45.2 and 50.5 to between 43.1 and 50.5, while increasing the likelihood of not being caught (to $r=0.95$ ) decreases the "window" to between 47.4 and 50.5. In this case it is clear that more comprehensive monitoring of disease reporting compliance by a government agency will increase the range of levels of compensation payments which incentivise farmers both to comply with disease reporting requirements and to undertake on-farm biosecurity measures, although more comprehensive monitoring could also be expected to be more costly. ${ }^{18}$

Finally in this section, consider the issue raised in Sect. 2 of the impact of the farmer's base level of likelihood of no disease outbreak on the incentive to incur the cost of on-farm biosecurity measures, and therefore on the scope for a level of compensation payments which incentivises both on-farm biosecurity and disease reporting compliance. For the Base Case this likelihood was assumed to be relatively high with $q=0.55$. Now consider the situation where a disease outbreak is instead relatively likely, with $\mathrm{q}=0.25$ (and $\mathrm{p}=0.45$ ).

17 Note that increasing and decreasing the fine for non-compliance (i.e. t) has similar effects on the "window" to those of decreasing and increasing $r$, so these results are not provided here. However, as mentioned previously, varying both $\mathrm{r}$ and $\mathrm{t}$ represents a potentially more socially desirable policy alternative. See Fraser (2002).

18 Once again I am grateful to an anonymous reviewer for pointing out this cost implication of decreasing $r$. 
Table 7 Sensitivity with respect to $\mathrm{q}$

\begin{tabular}{lllllll}
\hline & $\mathrm{D}(\% \mathrm{D} / \mathrm{M})$ & & & & \\
\cline { 2 - 7 } & $44(44 \%)$ & 45 & 45.3 & 46 & 47.8 & $48(48 \%)$ \\
\hline $\mathrm{q}=0.25$ & & & & & & \\
$\mathrm{R}=0.2$ & $\mathrm{BNR}$ & $\mathrm{BNR}$ & $\mathrm{BR}$ & $\mathrm{BR}$ & $\mathrm{BR}$ & $\mathrm{NBR}$ \\
$\mathrm{R}=0.5$ & $\mathrm{NBNR}$ & $\mathrm{NBR}$ & $\mathrm{NBR}$ & $\mathrm{NBR}$ & $\mathrm{NBR}$ & NBR \\
\hline
\end{tabular}

It was observed in Sect. 2 that in this case undertaking on-farm biosecurity measures has a positive impact on expected income (before cost) but, unlike for the Base Case, it also has a negative impact through increasing the variance of income. As a consequence, it was expected that such an increase in the base level disease likelihood would discourage farmers from undertaking on-farm biosecurity measures, and this expectation is confirmed by the results in Table 7.

More specifically, this negative impact of on-farm biosecurity measures on the variance of income means that the "window" is completely eliminated for the more risk averse farmer, and diminishes to between 45.3 and 47.8 for the less risk averse farmer. It follows that if the spatial distribution of an endemic animal disease creates such variations in the base level of likelihood of a disease outbreak between farmers in different regions, then the government agency faces a more complicated problem of incentivising these differently situated farmers to undertake on-farm biosecurity measures, and so the "single mechanism" option may not apply in this spatial context. ${ }^{19}$

\section{Conclusion}

This paper has examined the issue of compensation payments for farmers affected by an animal disease outbreak, and their role in incentivising farmers both to undertake costly onfarm biosecurity measures and to comply with disease reporting requirements. The paper was itself incentivised both by the observation of Hennessy and Wolf (2015) that "compensation must be sufficient to encourage early reporting but not so large as to discourage appropriate levels of biosecurity effort" (p. 1), and by their subsequent conclusion that "a single one-sizefits-all indemnity payment could not deal with both problems" (p. 9)—a conclusion which they noted was at odds with practice whereby "Animal health authorities have relied on a single mechanism-indemnities - to facilitate both ex ante biosecurity efforts and ex post reporting" (p. 10).

As a consequence, the aim of this paper was to develop a simple model of farmer decisionmaking in the presence of the threat of animal disease with a view to throwing some light on this conflict between the practice of animal health authorities and the conclusions of the existing literature regarding the scope for the "single mechanism" of compensation payments to incentivise farmers both to undertake on-farm biosecurity and to comply with disease reporting requirements.

This model was developed in Sect. 2 and then subjected to a numerical analysis in Sect. 3 for the purpose of illustrating the scope for compensation payments to create this dual incentivecompatible decision-making environment for farmers. This numerical analysis also included

19 See Hennessy and Wolf (2015) and associated references, particularly by David Hennessy, for further discussion of this spatial heterogeneity problem in disease management policy. 
an evaluation of the role of a set of policy and other parameter values in determining the extent to which a government agency could successfully incentivise both farmer actions of on-farm biosecurity and disease reporting compliance.

The findings of this numerical analysis included a demonstration that the potential existed for a range of levels of compensation payments to incentivise both farmer actions. Moreover, this range of levels could be influenced in the following ways by the value of parameters in the farmer's decision environment:

(i) The range is larger (smaller) for more (less) risk averse farmers

(ii) The range is larger (smaller) for less (more) costly on-farm biosecurity measures

(iii) The range is larger (smaller) for lower (higher) values for the "quick sale" of (unreported) diseased animals

(iv) The range is larger (smaller) for higher (lower) likelihood of being caught not complying.

Finally, across all the sensitivity analysis of parameter values this range of levels was confined to between 40 and $60 \%$ of the "market value" of animals.

In relation to the policy implications of this analysis, putting to one side the undeniable arbitrariness of most of the parameter values and instead focussing on the results relating to the ratio of compensation payments to "market value", it would seem that the current UK legal requirement for paying farmers compensation which is the equivalent of "market value" is almost certainly destructive of the incentive to invest voluntarily, and to any extent, in costly on-farm biosecurity. As a consequence, it can be concluded that the potential exists for considerable improvements in the cost-effectiveness of this policy by reducing the level of compensation payments below "market value".

In addition, consideration was given in both Sects. 2 and 3 to the issue of differences among farmers in the base line likelihood of a disease outbreak, such as would arise if an endemic animal disease had spatially differentiated levels of disease prevalence. In this case it was shown that a relatively high base line likelihood of a disease outbreak discouraged farmers from incurring the cost of on-farm biosecurity measures because such an action was risk-increasing. As a consequence, there may be no level of compensation payments which incentivises such farmers both to comply with disease reporting requirements and to undertake on-farm biosecurity, thereby casting doubt on the viability of the "single mechanism" of compensation payments to incentivise both farmer actions. However, in this case the appropriate policy response would seem to be not to discard the "single mechanism" of compensation payments, but rather to supplement it with region-specific subsidies towards the cost of undertaking on-farm biosecurity measures which apply in those areas with high disease prevalence. ${ }^{20}$

Finally, the approach in this paper of the government only choosing one policy parameter (the level of compensation payments) and fixing the other two policy parameters (the probability of being monitored for compliance with disease reporting and the penalty if caught not complying), while consistent with current policy practice in the UK, is clearly inadequate in the context of a complete evaluation of the socially desirable policy approach. Therefore, a further implication is for the need to review the current policy approach in the light of these limitations.

As a consequence, it seems reasonable to conclude that the existing practice of using the "single mechanism" of compensation payments to incentivise farmers both to undertake onfarm biosecurity and to comply with disease reporting requirements does have some analytical

20 Note in relation to the results reported in Table 7, that if the cost of B in this case was "subsidised" from 10 down to 8 , then the range of levels compensation payments which incentivise both on-farm biosecurity and disease reporting compliance is expanded from being non-existent to between 45 and 56.8 for $\mathrm{R}=0.5$. 
support, albeit in a relatively simple theoretical framework, even if it also is clearly in need of further analysis with a view to evaluating both its cost-effectiveness and its social desirability.

Acknowledgements I would like to thank the Guest Editor and two anonymous reviewers for their helpful comments and suggestions. In addition, I would like to thank seminar participants at the Universities of Kent and California, Davis, and at the UK's Department of Environment, Food and Rural Affairs. Finally, I would like to thank conference participants at the 2016 Annual Conferences of the Australian Agricultural and Resource Economics Society and the Agricultural Economics Society.

Open Access This article is distributed under the terms of the Creative Commons Attribution 4.0 International License (http://creativecommons.org/licenses/by/4.0/), which permits unrestricted use, distribution, and reproduction in any medium, provided you give appropriate credit to the original author(s) and the source, provide a link to the Creative Commons license, and indicate if changes were made.

\section{References}

Bardsley P, Harris M (1987) An approach to the econometric estimation of attitudes to risk in agriculture. Aust J Agric Econ 31(2):112-126

Bicknell KB, Wilen JE, Howitt RE (1999) Public policy and private incentives for livestock disease control. Aust J Agric Resour Econ 43:501-521

Fraser RW (2002) Moral hazard and risk management in agri-environmental policy. J Agric Econ 53(3):475487

Fraser RW (2015) Applications of principal-agent theory to agricultural land use policy: lessons from the European Union. Imperial College Press, London

Gramig BM, Horan RD, Wolf CA (2009) Livestock disease indemnity design when moral hazard is followed by adverse selection. Am J Agric Econ 91:627-641

Hanson SD, Ladd GW (1991) Robustness of the mean-variance model with truncated probability distributions. Am J Agric Econ 73:436-445

Hennessy DA, Wolf CA (2015) Asymmetric information, externalities, and incentives in animal disease prevention and control. J Agric Econ. doi:10.1111/1477-9552.12113

National Audit Office Report on the 2001 Outbreak of Foot-and-Mouth Disease (2002) www.nao.org.uk/ report/the-2001-outbreak-of-foot-and-mouth-disease/

Newbery DMG, Stiglitz JE (1981) The theory of commodity price stabilization. Clarendon Press, Oxford

Olmstead AL, Rhode PW (2015) Arresting contagion: science, policy and conflicts over disease control. Harvard University Press, Cambridge

Pope RD, Just RE (1991) On testing the structure of risk preferences in agricultural supply analysis. Am J Agric Econ 73:743-748

The Guardian (2001) Foot and mouth payments are too high. www.theguardian.com/uk/2001/aug/07/politics. footandmouth 